\title{
La identidad online. El proceso de adscripción y detentación identitaria desde los márgenes. Subversión y agenciamiento feminista
}

Online identity. The process of identity ascription and retention from the margins. Subversion and feminist agency

Xandra Garzón Costumero

IFS-CSIC xandragarzoncostumero@gmail.com

DOI: https://doi.org/10.15366/bp2021.28.010

Bajo Palabra. II Época. No28. Pgs: 217-236

Orcid: https://orcid.org/0000-0003-4139-8919 
Recibido: 30/09/2021

Aceptado: 12/11/2021

\section{Resumen}

El proceso de construcción identitaria online está afectado por un sistema de relaciones de género que insta al hombre a actuar bajo el modelo de masculinidad hegemónica y relega a la mujer a construir su identidad desde la otredad, de manera especular, teniendo como medida de todo al hombre. La socialización online ha adquirido una importancia capital sobre todo después de la pandemia de 2020, siendo el videojuego el principal producto de ocio de masas. Los datos indican que más del $60 \%$ de las mujeres esconden su género o se hacen pasar por hombres cuando juegan online y más del $77 \%$ afirma haber sentido frustración por su género al jugar. Esto es un grave inconveniente para la construcción identitaria de ambos géneros, y puede tener como consecuencias la expulsión de las mujeres de estos ámbitos. Ante ello, es necesario crear espacios en los que las mujeres puedan sentirse seguras y encontrar la libertad necesaria para desarrollar su personalidad online y su ciberyo, con autonomía y creación.

Palabras clave: identidad, género, videojuego, redes sociales, agenciamiento feminista.

\section{Abstract}

The process of online identity construction is affected by a system of gender relations that pushes men to act under the model of hegemonic masculinity and relegates women to construct their identity from otherness, in a specular way, being men the measure of everything. Online socialisation has acquired an essential importance, especially after the 2020 pandemic, being videogames the main mass entertainment product. Data indicates that more than $60 \%$ of women hide their gender or pretend to be male when play online and more than $77 \%$ feel frustrated about their gender when play video games. This is a serious drawback for the construction of identity for both genders, and one of its consequences can be the expulsion of women from these spaces. This problem requires the creation of spaces in which woman can feel safe and can find the necessary freedom to develop their online personality and our cyberidentity through autonomy and creation.

Keywords: identity, gender, video game, social networks, feminist agency. 


\section{Espacios físicos, espacios virtuales}

Quienes nos enfrentamos al estudio académico de las redes y de los comportamientos que se dan en ellas podríamos estar tentadas a pensar que en los espacios físicos no actuamos y no nos sentimos de la misma manera que en el ciberespacio, que nuestra construcción identitaria es independiente en ambas esferas. Podríamos concluir que son dos ámbitos separados y totalmente herméticos, con reglas dispares que nos llevan a actuar y a sentirnos de modos diversos, que nos desdoblan como persona, existiendo paralela y diferenciadamente un yo en cada esfera. O bien, y por el contrario, podríamos entender que, pese a que sean ámbitos distintos y diferenciados, nuestra identidad es unívoca, somos seres que podemos habitar en ambas esferas y nuestro comportamiento no depende sólo del lugar en el que nos encontremos, sino de quiénes somos en realidad y qué condicionantes modulan en cada ocasión nuestras respuestas, nuestra manera de percibirnos y de mostrarnos.

¿Nos convertimos en personas distintas cuando estamos ante una pantalla? ¿Es la misma nuestra identidad social que nuestra identidad online? ¿Tenemos dos identidades independientes según el (ciber)espacio que habitemos? Todo parece apuntar a que no, pero la pregunta más relevante en este punto sería: ¿̇realmente son dos identidades distintas o simplemente estamos ante dos entornos con reglas diferentes, con consecuencias (incluso jurídicas) distintas, con responsabilidades diversas que hacen que nuestra identidad sea expresada de otro modo? ¿Somos dos entes distintos (mi yo social y mi yo online), o uno solo hibridado? En el presente texto vengo a defender la segunda tesis, la de la hibridación, la del yo cyborg. Entiendo el cyborg como un organismo cibernético, un híbrido de máquina y organismo, una criatura de realidad social y también de ficción. La realidad social son nuestras realidades sociales vividas, nuestra construcción política más importante, un mundo cambiante de ficción (...) las fronteras entre ciencia ficción y realidad social son una ilusión óptica (Haraway, 2020:2-3). Puede que algunos de los factores implicados en la construcción de nuestra identidad social sean reconocibles en la formación de nuestra identidad virtual, por tanto, se pueden establecer paralelismos entre la vida real y la virtual que conllevan a patrones comunes de identidad en el individuo (Muros, 2011). 
Remedios Zafra (2010) apuntaba ya en este sentido. Sus palabras se vuelven aún más interesantes tras la experiencia de una pandemia que nos ha encerrado en casa y nos ha hecho reflexionar sobre nosotras mismas como individuos que habitan también la red. Dice así:

En todo caso, no crean que llevo al extremo esta sentencia. No soy suficientemente temeraria para una memorable vida radical, de enclaustramiento. Asumo mi común ambigüedad y sólo hacerlo me lleva a defenderla como virtud. Tal es así, que, aunque habitualmente elijo el cuarto propio conectado, salgo con frecuencia de casa, sigo tocando a mis amigos y comparto abrazos con quienes quiero. A estas alturas, sé lo que es el cuerpo que siente y ama. La intensidad de sus pulsiones, el tacto y el pálpito ajeno junto al propio. Sin embargo, sí percibo que los afectos, los deseos, las relaciones, y claro está, la creatividad y la reflexión, acontecen en esta época con otros matices, se acomodan de otra forma a nuestros cuerpos, a la manera de sentir y pensar al otro. Y, como Woolf, creo que cuando cambian las formas de relacionarnos hay un cambio simultáneo en la escritura, en la economía y la política; como respuesta, un cambio en nuestra idea del yo. (Zafra, 2010:191)

$\mathrm{Y}$ es que las personas que somos en cada momento tienen relación con el medio que habitamos, con el sitio o el ciberespacio donde desarrollamos nuestras relaciones, los lugares donde somos también forman parte de lo que somos.

\section{Identidad, identidades}

Al hablar de identidades hablamos a la vez de individualidad y de grupos de individuos, así como del yo frente al nosotros y al vosotros. Hablar de identidades online además es hablar de la soledad frente a la compañía de la pantalla (de las personas tras esa pantalla), de pantallas amigas y de pantallas hostiles, de los míos y de los tuyos. De lo que formo parte queriendo, sin querer y por imposición externa. De lo que elijo ser y de lo que soy para los demás sin elección (véase, por ejemplo, Gamero Cabrera, 2012). Es hablar de grupos, pero no solo de grupos homogéneos fácilmente identificables por sus intereses, también de grupos que se forman al amparo de la otredad, por exclusión, por obligación en muchos casos y también es hablar de grupos que se interrelacionan desde los márgenes y que responden en su composición y funcionamiento al concepto de agenciamiento propuesto por Deleuze y Guattari (1985).

Aunque con un enfoque más tradicional y politológico, una teoría estática en su planteamiento como la del clivaje (cleavage) o fractura social de Lipset y Rokkan (1967) no nos sirve para estudiar los grupos de adscripción identitaria online en el sentido que proponemos en este texto. Consideramos, por el contrario, que las 
identidades colectivas son mucho más líquidas hoy en día, mudables e inconsistentes tal como expone Bauman (2008) y que necesitamos entender el ecosistema online como un modelo rizomático, siguiendo a Deleuze y Guattari (1985), para poder darle sentido a las adscripciones identitarias online. Los grupos de personas que se mueven por unos intereses comunes anclados en características medibles y fijas no tienen sentido en este análisis, requerimos pues del concepto de agenciamiento y del de rizoma para comprender, en primer lugar, de qué modo las mujeres hemos sido puestas en cuestión, reiteradamente, como individuos autónomos en redes, con especial inquina en el mundo del videojuego. En segundo lugar, también tenemos que comprender de qué manera estamos subvirtiendo ese orden y hemos hecho de la sororidad y de la ironía nuestra coraza para resistir los envites en la red, cuestión con la que concluiremos este texto.

Zygmunt Bauman (2008:10-11) explica que nos encontramos ante dos tipos de comunidades: por un lado, "comunidades de vida y destino cuyos miembros viven juntos una trabazón indisoluble" y, por otro lado, comunidades unidas exclusivamente por ideas o principios diversos. Para el autor, son las segundas las que suscitan la cuestión de la identidad. Uno se conciencia de que la "pertenencia" o la "identidad" no están talladas en roca, de que no están protegidas con garantías de por vida, de que son eminentemente negociables y revocables. Y de que las propias decisiones de uno, los pasos que uno da, la forma que tiene de actuar (y la determinación de mantenerse fiel a todo ello) son factores cruciales en ambas. En otras palabras, nadie se plantearía tener una identidad si la pertenencia siguiera siendo un destino y una condición sin alternativa. ${ }^{1}$

De igual manera y continuando con el argumento: no se puede ser violento en redes sociales: se es violento, y esa violencia cristaliza en los espacios virtuales porque allí se dan las condiciones necesarias para ello. No se puede ser machista en los videojuegos: se es machista, y eso se pone de manifiesto especialmente en un entorno en el que las consecuencias de cada actitud van a ser mucho menores, como en las redes, en los videojuegos, en Twitter... En definitiva: el universo red que hemos creado no nos hace peores personas, no saca lo peor de nosotros; al contrario, nos hace conocernos mejor y nos permite explorar facetas de nuestro yo que emergen cuando estamos detrás de nuestra pantalla, que surgen cuando disfrutamos del anonimato que da ese cibervelo. Esta visión individualista de nuestra personalidad en redes tiene una interpretación social, más interesante y es que el estudio y análisis de los comportamientos e identidades que mostramos en redes son muy útiles para las ciencias humanas, sociales y jurídicas, y puede ser muy relevante para entender

${ }^{1}$ En este caso y en los siguientes las cursivas son de la autora del artículo para enfatizar. 
mejor nuestra realidad social en los escenarios virtuales y, por extensión, en los analógicos.

Si además de virtual el escenario es no real, la utilidad del estudio de nuestra identidad es incluso mayor. Con "espacios virtuales no reales" me refiero a espacios que simulan pertenecer a una realidad apartada de aquella en la que vivimos, que funciona bajo sus propias reglas físicas, sociales, históricas y cuyo paradigma es el videojuego. Con "espacios virtuales reales" me refiero a aquellos que, pese a estar alojados en la red, pretenden ser un reflejo más o menos exacto de la realidad no virtual que se da fuera (las redes sociales o los foros podrían ser un ejemplo). Si tengo una actitud violenta en chats de Internet en los que actúo bajo un pseudónimo, pero, por el contrario, jamás he actuado de manera violenta en mi vida física ¿quiere esto decir que no soy violenta? No, quiere decir que soy violenta en esa circunstancia, situación o coyuntura, bajo estos condicionantes concretos. Sería además bastante útil que tuviera en cuenta esta faceta de mí misma que la red me ha permitido poner de manifiesto. Si expongo en un entorno virtual real como Instagram una imagen de mi vida cuasi perfecta que poco tiene que ver con la realidad, ¿quiere eso decir que la que aparece allí no soy yo? No, quiere decir que bajo determinadas circunstancias la parte de mi vida que me gusta exponer en la red es esa, que es una visión parcial o falseada de mi vida, una faceta más que se superpone a la realidad física en la que vivo y que poco tiene que ver con ella si se analiza de manera aislada. Dada esa pretendida impostura que se da en los espacios virtuales reales, me parece más interesante el estudio de los espacios virtuales no reales, por lo que tienen de auténticos en comparación con el pálido reflejo que los espacios virtuales reales son de la realidad. Me interesa el hecho de que se dé una disociación con el avatar, que no tiene por qué representar mi yo analógico. Nuestras realidades aparecen entretejidas en capas de identidad más pequeñas, que se suceden secuencialmente; y todas ellas, evolucionando y cambiando forman lo que puedo considerar mi identidad.

Utilizando la categorización extraída de la obra del sociólogo George H. Mead (1928), el yo que exponemos en las redes sociales está más de cerca del selfespecular, del looking glass self, ya que viene posibilitado por nuestra capacidad de objetivizarnos, de vernos desde fuera y considerarnos a nosotros mismos objetos a la par que sujetos. Sin embargo, esa objetualización de nosotros mismos que llevamos a cabo en redes sociales, esa capacidad de juzgarnos como objetos que, a su vez, van a ser juzgados por los demás, ya viene hecha, en el videojuego, en mi avatar. En los videojuegos no tengo que mostrarme ante los demás tal como esperan verme, no tengo necesidad de pasar por ese proceso mental, ya que muchas veces el personaje o avatar no soy yo, pero el personaje que expongo en redes sociales sí. El punto de inflexión viene cuando reflexionamos no sobre mi avatar en un videojuego y la 
representación más o menos fiel, más o menos estereotipada que puede estar haciendo de mí -o incluso si puedo verme representada siquiera remotamente en ese personaje que ahora manejo-, el problema aparece cuando el hecho de expresar mi identidad como mujer que juega sí supone una diferencia para el resto de jugadores y esto me lleva a ocultar mi género como jugadora porque en este ciberespacio no es seguro mostrarlo. Sobre esto volveremos después.

\section{Las idénticas, los iguales}

Es importante destacar en primer lugar que para poder hablar de identidad es necesario que exista un grupo que entendamos como grupo de iguales. Hablar sobre identidad, al fin y al cabo, es hablar sobre adscripciones a grupos y no solo a esos grupos a los que estoy materialmente ligada (ser de Guadix, ser blanca, ser de clase obrera...), también a esos grupos que he elegido que me definan (determinada ideología, mi identidad de género...). Si esos rasgos no tuviesen relevancia para los otros, no serían algo relevantes para mí en la actividad online. Ahora bien, este hecho adquiere una importancia capital para los videojugadores varones, que modulan en muchos casos su actitud dependiendo de que lo que tengan delante se defina como jugador o jugadora.

¿Ser de un lugar, pertenecer a un sitio (ser del sur o del norte, de pueblo o de ciudad...), es lo mismo que ser de un sitio en la red? ¿Se puede estar (como sinónimo de habitar) en una red social? ¿Se puede ser de un videojuego? ¿Pueden estas cosas determinar mi forma de ser, mi forma de percibirme a mí misma o mi forma de presentarme ante el resto? Desde luego que ser de aquí o de allá sí que lo hace, a veces, incluso, ser de un lugar nos lleva a defender cosas muy peregrinas cuando se ataca a la que consideramos nuestra tierra. Así, en ocasiones, ser de un sitio nos hace percibirnos a nosotras mismas bajo unos estereotipos establecidos, injustos muchas veces, poco apropiados otras, alejados de la realidad la mayoría de ocasiones. Además, se genera muy a menudo un sentimiento de protección hacia la tierra como si esa tierra también fuera parte de mí misma, debiéndole una especie de lealtad, inconsciente en la mayoría de los casos. Nace así un sentimiento que nos ancla, que da sentido a nuestra existencia frente al resto. Nos diferencia de unos y nos acerca a otros.

Teniendo en cuenta que una gran parte de la vida la pasamos frente a la pantalla no es extrańo que nos preguntemos por esos sentimientos que pueden surgir sobre mi pertenencia online, mi selfonline. ¿¿Funciona bajo los mismos parámetros? La tierra, entre muchos otros factores como la clase social, la ideología política o nuestra 
expresión de género nos definen, entonces, ¿̨pertenecer a cualquier red también lo hace? Para Muros (2011) somos, de un modo u otro, seres históricos, vitalmente unidos al espacio y al tiempo en el que vivimos. De ahí que la identidad ha de ser entendida como una construcción de identidades, donde múltiples factores (como actividades, experiencias, organizaciones sociales, relaciones culturales históricamente específicas) se combinan para que el individuo (o colectivo) le dé sentido. Para Munné (2000) alguien puede autoreferir-se, entender-se a través de diferentes situaciones, lo que le convierte en un ser plural. Celia Amorós, parafraseando a Rossana Rossanda lo explica así:

Las mujeres sienten que su desigualdad -lo dicen continuamente- viene de su antigua cultura introyectada, que está en los orígenes de su opresión, anterior a la leyes y más fuerte que estas. La conciencia común las juzga, a pesar de todo, como no iguales: por lo tanto, en efecto, no lo son. [...] La paridad de derechos entre hombres es paridad entre individuos; y qué es el individuo resulta bastante claro para el hombre. Este posee una historia, ha tenido expresiones culturales, se ha expresado en valores, normas. Pero qué es el individuo mujer ya no está tan claro. No tiene la misma historia, no se ha expresado a través de una escala propia de valores, no ha tenido normas ni formaciones propias. (Amorós, 1987:113 y127)

Y pese a que Amorós se refería principalmente a la representación política de la mujer, entiendo que las identidades involucran también, en cierto sentido, el concepto de representación, no política, pero sí social. El catálogo de identidades online que se nos ofrece a las mujeres es limitado y tiene como medida de todo al varón, al individuo por excelencia: a los iguales. De este modo nuestra identidad se construye frente a la de ellos, a la sombra: somos las idénticas. Se nos sigue sin considerar un equivalente. No se nos mira a los ojos, ni cuando Celia Amorós hablaba de representación política ni ahora que hablamos de identidad online.

Desde hace mucho tiempo, este tipo de reflexiones se han llevado a cabo desde el feminismo y hay autoras como Remedios Zafra (2010) que en su obra ofrecen un catálogo de identidades online que subvierten el orden establecido, que apuestan por la sororidad. Siguiendo sus tesis, cabe destacar que la revolución no es la representación online, sino la unión, la sorora comunidad que rompe así las normas y reglas que me alejan de la libertad de elegir quien ser. Zafra nos da un catálogo de identidades posibles, pero no es un catálogo cerrado como hasta ahora se nos ha ofrecido, por ejemplo, en las narrativas videolúdicas; por el contrario, ella explora diferentes maneras de sentirse mujer en Internet (netiana) abriéndonos un abanico de posibilidades que nos empuja a explorar, a desarrollarnos libremente, que no nos constriñe, sino que nos abre diferentes opciones en las que poder encaminar nuestra exploración del yo online. 


\section{El videojuego agente socializador}

Habitar los espacios virtuales de esta sociedad digital en la que también vivimos, transitarlos, nos define, porque estar en ellos es una elección voluntaria y consciente, al igual que lo es abandonarlos cuando dejan de tener utilidad para nosotras. Estar virtualmente en una red social o jugar a un videojuego online también es voluntario y ello genera pertenencias. Pertenecer a un grupo o a una comunidad virtual implica compartir -bien en su totalidad, bien parcialmente- el núcleo de representaciones sociales (por ejemplo, creencias, opiniones, actitudes) que los define (Jodelet, 1986).

El videojuego debemos entenderlo hoy en día no solo como un producto cultural de masas, también es un agente de socialización importantísimo para las generaciones más jóvenes, y cada día es más intergeneracional debemos apuntar. El mundo del videojuego tiene su propia idiosincrasia: igual que el resto de agentes socializadores funcionan bajo unas reglas propias, el videojuego también lo hace.

Las dinámicas que se adoptan a la hora de jugar a videojuegos hacen que se generen comunidades o grupos de personas con mucha facilidad, en primer lugar, porque los videojuegos con un componente social se prestan a ello. En segundo lugar, quienes juegan lo hacen para distraerse, en momentos de ocio, momentos en los que se tiene una actitud distendida que invita al contacto social. La edad de las personas jugadoras puede explicar también este fenómeno, y es innegable que las propias dinámicas de juego en muchas ocasiones actúan como catalizadores de ese contacto social del que hablamos.

Es necesario formar comunidades de juego para alcanzar determinados objetivos en distintos videojuegos, como juegos de supervivencia -que tanto desarrollo están teniendo en la última década-, pero también en juegos de rol tipo MMO (Massive Multiplayer Online), una tribu en Ark Survival Evolved (Studio Wildcard 2017), una hermandad en World of Warcraft (Blizzard 2004), una compañía en New World (Amazon Game Studios 2021), sin los cuales no se puede acceder a una parte muy importante del contenido del juego. Esto hace que el componente social en muchas ocasiones sea una parte fundamental de la experiencia de juego, y que la mujer lo tenga más difícil para su acceso y disfrute.

Este tipo de juegos suelen permitir dos formas de juego, con sus lógicas excepciones: por un lado, se da el modo "Jugador contra el entorno" o, por sus siglas en inglés, PVE (player versus enviroment) en el que un jugador o un grupo de jugadores luchan contra los enemigos que el propio videojuego les proporciona, lo que conlleva dinámicas cooperativas de juego. Por otro lado, está el modo "Jugador contra jugador", o PVP en sus siglas en inglés (player versus player), en el que el jugador 
o grupo de jugadores se enfrentan a otros jugadores que serán sus rivales, lo que genera dinámicas competitivas. Tanto en PVE como en PVP, si se juega en equipo, es muy necesario mantener contacto con los compañeros para poder llevar a cabo una estrategia que permita coordinar a los miembros del equipo y así lograr ganar al equipo contrario. Es tal la importancia de esta comunicación dentro del equipo que se han creado medios tecnológicos exprofeso para tal fin, como los chats de voz Discord o Team Speak. Está claro que, si aproximadamente el 60\% de las mujeres esconden su género a la hora de jugar, o bien se identifican como hombres (Reach3 Insights, 2021), es improbable que accedan a estos chat de voz con la misma libertad que los varones. Evitarán formar parte de este tipo de comunidades, y al ser necesarias para completar objetivos del juego, su experiencia se verá irremediablemente dañada. Siguiendo el mismo estudio, cabe destacar que aproximadamente el 77\% de las encuestadas afirman haber tenido algún tipo de frustración al jugar debido a su género. La falta de libertad para mostrar el género crea un proceso de degradación social para la mujer, lo que actúa como una fuerza centrípeta que hace que se sienta ajena y que, en el mejor de los casos, merme su interés por el juego y, en el peor, que la expulse.

Además de este ocultamiento o falta de libertad para mostrar la identidad de género para evitar las consecuencias que ello acarrea, se produce otro fenómeno interesante: se infantiliza, denuesta y desprestigia absolutamente cualquier parcela del videojuego en el que la mujer haya podido tener interés, y se le hace saber que ese no es su lugar, no es un espacio de socialización que le pertenezca o en el que se vaya a sentir cómoda (Garzón, 2021). Videojuegos típicamente asociados al público femenino, como la saga de los Sims (EA 2000), o la saga de Animal Crossing (Nintendo 2001), por poner un par de ejemplos, son considerados videojuegos de segunda. También está muy extendida la práctica de la jugadora que no ha sido llamada a jugar, la jugadora vicaria que vive la experiencia a través de otro, la mujer que prefiere ver a otra persona (habitualmente su pareja varón, un hermano o un amigo) jugar. Ella comprende las mecánicas de juego, tiene las dinámicas claras, le gusta la parte narrativa y lúdica; pero lo experimenta a través de otro, de manera pasiva. Esto es, ve jugar al otro sin exponer su yo real en el juego ni a los posibles jugadores que haya en él, sin experimentar la parte activa.

En conclusión, el hecho de que se lleven a cabo comportamientos denigrantes para con las mujeres (o con varones que no desplieguen la masculinidad de modo suficiente) y que además esto sea una práctica bastante extendida, normalizada y no censurada por los varones que no las practican hace que el medio de los videojuegos sea indiscutiblemente hostil para la mujer y para toda disidencia de género. 


\section{Menos individuos, menos personas, menos ciudadanas online}

Nuestro día a día, nuestros hábitos y costumbres diarias se desarrollan cada vez más en entornos virtuales online: trabajo, ocio, relaciones familiares... Máxime cuando la pandemia que comenzó en 2020 nos trajo una nueva normalidad en la que hemos cambiado muchos de los espacios físicos tradicionales por espacios virtuales mucho más seguros para evitar contagios. Nuestras experiencias vitales se están desarrollando, por ende, en este tipo de espacios, que no son más artificiales que la sala de reuniones del tercer piso de nuestra oficina o despacho, pero que sin duda funcionan bajo otras reglas y que afectan a nuestro modo de ser, a nuestro modo de percibirnos y mostrarnos, del mismo modo que los espacios físicos tradicionales.

La masculinidad imperante en los entornos relativos al videojuego que aleja a muchas niñas y mujeres de este tipo de ocio, en consecuencia, las aleja de una industria que es un negocio boyante y con capacidad incluso para emplearlas, retroalimentando el desinterés al generar contenidos masculinizados. Lo deseable por el contrario es que muchas más nińas, pudieran, quisieran, y fueran llamadas a entrar en un mundo tan estimulante, tan grande, tan divertido, tan liberador y con tanto futuro. Las tecnologías tal como expone Judy Wajcman (2004) tienen género, tanto por su diseño como por su uso.

Como por ejemplo argumenta Amorós (1987), la mujer, en la historia del pensamiento, no ha sido considerada igual al hombre de manera formal hasta hace poco tiempo, y solo en determinadas sociedades se les ha dado un estatus legal igual al del hombre, lo que en ningún caso garantiza una igualdad plena. Los filósofos clásicos pusieron sobre la mesa que lo que nos hace humanos es la razón, y esta no se le presuponía a la mujer hasta hace muy poco tiempo. La mujer era menos persona que el hombre. La legitimidad política que llegaría a convertirnos en ciudadanos, sujetos de derechos y de deberes, también dejó fuera a la mujer en primera instancia. ${ }^{2}$ Nuestros sistemas legales no repararon en nosotras como sujetos hasta tiempos relativamente recientes. Por esto cabe mantener que siempre ha habido "individuos más individuos que otros". No es raro que a las mujeres se nos ningunee también en estos espacios virtuales en los que, cada día más, desarrollamos nuestras rutinas diarias, en ese espacio que es público y debería ser neutro pese a que lo transitamos desde nuestros cuartos propios conectados (Zafra, 2010) que son el espacio privadísimo por excelencia.

No podemos concebir al ciudadano, a la persona, al individuo sin el mundo que le rodea, sin los espacios en los que habitamos, la tecnología que utilizamos y

2 Este mismo tema ha sido contemplado por Isabel Gamero en este mismo monográfico. 
los flujos relacionales que nos rodean. Si este entorno deviene (o nace ya) viciado y hostil para la mujer, entonces se dan cambios no solo nuestra relación con el medio cambia respecto a la del hombre, sino que nosotras mismas cambiamos como personas, como individuos. Nos concebimos como distintas y se nos percibe como diferentes, como un grupo de idénticas (no como individuos) que se encuentran en el terreno de la otredad.

Las identidades, al fin y al cabo, intentan poner orden en esa marańa de atributos y percepciones que nos definen, y que ni siquiera nosotros mismos comprendemos con claridad. El fracaso se ve venir de lejos si lo que procuramos es definir la esencia de lo que somos, aquello que unívocamente nos define como persona, pues las identidades tan solo podrán ser pálidos reflejos de aquello que somos en realidad, reflejos parciales, que pueden ser útiles en determinados contextos, pero que no son monolíticos. Cambian, fluctúan, adquieren importancia o se desinflan. Una identidad puede ser una foto fija del yo en el ahora, pero no me definen a futuro, no pueden hacerlo. Las líneas de fuga que escapan de las narrativas mayoritarias hacen que esas identidades sean cambiantes, y lo que hoy puede definir mi yo cómodamente, puede no hacerlo mañana.

La única manera, pues, de ser individuos es hacerlo en relación al mundo que nos rodea, sea virtual o real, en el que la diversidad y el cambio constante son innegables. Necesitamos definirnos para crear una narrativa coherente que dé explicación a nuestra vida, a nuestra necesidad de encontrar iguales en los que vernos reflejados, la necesidad de diferenciarnos del otro, la necesidad de ser individuos.

El concepto de agenciamiento de Deleuze y Guattari (1985) nos sirve para comprender las relaciones interpersonales que se dan en los márgenes de la red, gracias a ella y sobre ella. Estas relaciones implican componentes diversos y heterogéneos, se relacionan entre ellos y con el medio (o los medios) en los que se encuentran, que son individuos, tecnología y espacios. Este tipo de sistemas relacionales son capaces de generar sinergias totalmente nuevas, que nos proporcionan capacidades concretas. Es innegable que hay otros agenciamientos que también infieren en este funcionamiento, pero las relaciones entre sus elementos internos pueden estar exentas de trabajar bajo las lógicas de agenciamientos mayores, y seguirán desarrollándose, pues su manera rizomática de crecer no puede ser territorializada. Lo importante son las relaciones que se establecen y las capacidades concretas que nos otorgan.

Las herramientas, los artefactos y tecnologías de las que disponemos hoy nos permiten desarrollarnos y establecer vínculos. Ahora bien, si estas herramientas, artefactos o técnicas están diseñadas sin contar con una parte de la población, entonces van a dejar fuera de sus lógicas a esa parte, y nuestro desarrollo como individuos se va a ver afectado necesariamente. De ahí la importancia de generar espacios y 
artefactos no transidos por un sistema de relaciones de género concreto e injusto, que es el que impera en nuestras sociedades. De este modo, las identidades que como personas podemos adoptar requieren del mundo material para ser expresadas, requieren poder hablar con libertad en la calle o en un chat online, requieren poder expresarte como mujer en el trabajo, en el gimnasio, y en una partida de League of Legends, y requieren que se nos reconozca sin imposición exterior alguna. Requieren, además, que se nos ofrezca un catálogo de avatares que no se encuadren en los mismos tropos femeninos que llevamos sufriendo durante los últimos siglos y que no invitan a dejar correr la imaginación sobre quién puedo o quién quiero ser.

Si enfocamos el análisis de los videojuegos desde esta perspectiva de género, podemos apreciar claramente cómo en este medio el ser mujer de los personajes femeninos se encuentra anclado en los estereotipos más burdos y consolidados de nuestra cultura: las mujeres aparecen o bien hipersexualizadas desempeńando el papel de femme fatale (Ivy en Soul Calibur II) o el de Lolita (Enfermera Angie en Trauma Center: Second opinion), o bien desempeñando el papel de cuidadoras (Katia en El Profesor Layton: la caja de Pandora) o gestadoras (Imagina ser mamá), o bien el de dama en apuros (la clásica princesa Peach de la saga de Super Mario Bros.) Mientras los personajes femeninos prácticamente en su totalidad pueden subsumirse en estos tres estereotipos (Ready for sex -Lolita o femme fatale-, cuidadora/gestadora y dama en apuros); los personajes masculinos no siempre se encuentran estereotipados y, cuando lo hacen, pueden subsumirse bajo una gama muchos más amplia de estereotipos que los personajes femeninos: Ready for violence (el estereotipo más común), el héroe amable, el científico loco, el anciano sabio, el rompecorazones (Don Juan) o el caballero al rescate son seis de los más habituales. De este modo, los videojuegos están reproduciendo de una forma casi caricaturesca (exagerándolos a veces hasta lo grotesco, como en muchos videojuegos de lucha o de acción) los modelos de masculinidad y feminidad tradicionales que aún continúan presentes en nuestra cultura (Rubio y Cabañes, 2012) y que, aunque estereotipan a ambos géneros, a ellos les da mucha más libertad de elección que a nosotras.

Para subvertir esta realidad necesitamos llevar a cabo un proceso de deconstrucción que nos permita dejar atrás las confrontaciones dialécticas del género, pero, muy a nuestro pesar, las tendencias parecen ir en dirección opuesta, la realidad postcuerpo que presuponíamos sería la red de redes, ese espacio en el que la mujer no necesitaría del cuerpo para ser, se ha convertido en una ciberrealidad hipercorpórea: en una sobreexposición de los cuerpos, en unas redes sociales que hacen de la imagen su razón de ser y crean estándares de belleza imposibles de conseguir e insanos que monopolizan los discursos y que crean filtros que mejoran mi cara y mi cuerpo y generan insatisfacción, cambio constante. El sistema neoliberal juega 
con las frustraciones que esta realidad hipercorpórea crea, y procura vendernos todo aquello que, si bien no podemos ser, sí podemos comprar.

\section{Identidades como medio de subversión o de control}

Sin el entorno necesario no se desarrollan las capacidades posibles. En un entorno hostil se desarrollarán capacidades que nos permitan lidiar con ese entorno, pero no otras que quedarán tapadas, inactivas, ignotas. Al mismo tiempo, a las mujeres se nos juzga por no desplegar tales capacidades, se nos identifica con la falta de desarrollo de algunas de ellas, como si hubiéramos tenido la capacidad real de desarrollarlas en el entorno (supuestamente neutro) en el que habitamos. La conclusión inevitable es que realmente no (todos) somos individuos con capacidad para expresarnos como tales en la red. Hay patrones y modelos de comportamiento que nos afectan, y tomamos como propias determinadas identidades prestadas que, en realidad, nos son ajenas y pueden no expresar con fidelidad aquello que podrían mostrar si el proceso deviniese libre.

Siempre que adoptamos (o detentamos) una identidad no debemos olvidar que son identidades ya establecidas por el sistema. El proceso de creación de identidades no es automático y una identidad totalmente nueva, totalmente otra, no emerge en la sociedad de la nada, precisamente porque las identidades nos acercan a otras personas con las que compartimos y así crecen y se transforman, rizomáticamente, como ya hemos dicho con anterioridad. Lo que nunca sucede es que las identidades nazcan aisladas de todos los procesos sociales, políticos e históricos en los que se ven envueltas que son, al fin y al cabo, los que les dan sentido. Por este motivo no debemos constreñir las identidades, porque son una manera más de luchar contra el propio sistema (aunque lo hagan desde dentro) y es necesario dejar que crezcan, evolucionen, cambien y se desarrollen libremente. En este sentido y como mantienen Deleuze y Guattari:

El valor radica, sin embargo, en aceptar el huir antes que vivir quieta e hipócritamente en falsos refugios. Los valores, las morales, las patrias, las religiones y esas certezas privadas que nuestra vanidad y nuestra complacencia nos otorgan generosamente, son otras tantas estancias engańosas que el mundo habilita para los que piensan mantenerse así de pie y en descanso, entre las cosas estables (1985:297).

Podemos llegar a pensar que al hacer nuestra, detentar o adoptar una identidad estamos siendo encasilladas en categorías predefinidas y, en el fondo, así es, aunque esas identidades pretendan subvertir el orden establecido y darnos nuevas maneras 
de expresar nuestro yo. Esas categorías le dan sentido a un mundo cambiante y sin ellas no podríamos acabar de entender nuestro devenir como personas. Nos encasillamos en categorías predefinidas, sin la capacidad siquiera para crearlas, solo para elegir entre las ya expuestas, haciendo gala de ello en redes sociales, consumiendo la información que mi cámara de eco basada en mi identidad me proporciona. Al mismo tiempo, los medios de comunicación de masas saben, a partir de nuestra identidad, qué información es la que pueden venderme, cual me interesa y cuál no; y así nos vuelve a poner en nuestro lugar, no como ciudadanas, sino como consumidoras. Volvemos a ser las idénticas. Cabe reconocer que, en este sentido, los hombres también son los idénticos, pero al menos tienen agencia para autodefinirse, que es lo que nos convierte en individuos. Siendo justas, debemos tener en cuenta que en nuestra sociedad es la creación de capital y no el hombre lo que se encuentra en el centro de todo, solo que el hombre lo tiene más fácil para desarrollarse como persona, como individuo en este espacio. Cualquier intento de subversión es reconducido por el capitalismo en identidades que, en lugar de liberar, son fácilmente explotables, como el capitalismo verde, el pinkwashing y logos de marcas con la bandera arcoíris.

Quienes habitan las redes no son seres extrańos, somos nosotros mismos, nosotras mismas, con la cara tapada por un velo virtual, que puede ser más o menos tupido, que puede ser una máscara en lugar de un velo y que crea un juego de identidades ocultas y reveladas digno de atención. Lo que vemos en las redes, en los chats ingame, en los chats de voz, en Twitter, en Facebook o en Instagram es un eco bastante preciso de la sociedad, un eco que a veces puede aumentar las partes más oscuras de algunas personalidades por la ausencia de consecuencias o el desconocimiento, en muchos casos, de estas. Sin embargo, este eco es medianamente fiel a la realidad social que refleja, incluso, a veces, surge la duda de si no es más real ese eco que damos con la cara tapada por el cibervelo que nuestro yo en el mundo no virtual; ya que, el cibervelo por un lado protege nuestra identidad y por el otro expone nuestros comportamientos, esos que no mostraríamos en un espacio real.

\section{La agencia* La esperanza. La subversión. Las Terebitas}

El borrado de la mujer del que tanto se está escuchando hablar en entornos académicos en los tiempos recientes no es más que el eco de quien observa con miedo el concepto de mujer en su devenir en el tiempo. Las categorías nos permiten crear narrativas que pretenden ser estables, y que pretenden definirnos de forma monolítica, pero no son más que esas "estancias engañosas que el mundo habilita 
para los que piensan mantenerse así de pie y en descanso", como decían Deleuze y Guattari (1985:297). Intentar hacer estático un concepto en nuestro mundo es intentar tapar el Sol con un dedo. La nostalgia de los conceptos que eran y ya no son es lícita, pero no podemos petrificar ideas con las que nos sentimos cómodas y negar cualquier tipo de cambio o advenimiento, ni dar la espalda a conceptos e ideas nuevas con las que otras personas se pueden sentir más cómodas, porque su realidad probablemente sea otra diferente. Además, para desarrollar las capacidades que se necesitan en nuestro mundo es necesario olvidarnos de los conceptos que petrifican capacidades.

Colectivos ciberfeministas como las VNS Matrix imaginaron la revolución digital feminista en otros términos, la subjetividad postcuerpo que se nos ofrecía era liberadora y empoderante, la relación entre mujer y tecnología que atisbaron es todo lo contrario al Only Fans que nos ofrece el capitalismo (que no es más que un dispositivo de dominación y control, como cualquier otro, por más que se pretenda vendérnoslo como una manera empoderante para la mujer de generar capital).

Sin embargo, existen puntos de fuga, maneras de desafiar el orden establecido, las maneras de relacionarnos con la tecnología y entre nosotras mismas que sí son genuinamente empoderantes, como decía Alma Mahler: "Con garras de acero voy haciendo mi nido robado, cada genio no es para mí más que la paja que me hace falta, un poco de botín para mi nido" (1997:189).

Para concluir, me gustaría aludir a uno de esos puntos de fuga, una de esas plumas obtenidas con garras de acero que nos permiten hacer nuestro nido robado, un ejemplo de agenciamiento entre mujeres y tecnología que desafía las normas, los tiempos y las reglas socialmente establecidas que nos constriñen. Se trata de la revista web Terebi Magazine, cuyas autoras se definen a sí mismas como Señoras hablando de videojuegos. Sin seguir los ritmos frenéticos de la crítica cultural estándar, ellas se permiten hacer reflexión desde la calma, desde el cuidado, desde el respeto y desde la disidencia de género. Poniendo el foco en sus autoras e ilustradoras, es un espacio de pensamiento online, de entre tantos otros que hay haciendo las cosas de otra manera, que merece la pena ser señalado. En este medio han crecido y se han ido desarrollando de manera rizomática: sus narrativas son transmedia, ${ }^{3}$ y se desarrollan paralelamente en formato escrito, en ilustraciones, en podcast. En ellas encontramos un espacio de resistencia, un desafío dentro del mundo de la crítica y la reflexión. Es uno de esos espacios que anunciábamos al comienzo del presente texto: en los que no solo podemos vernos seguras y representadas, sino desde los que podemos afectar y encontrar la libertad para crear, para reflexionar. En espa-

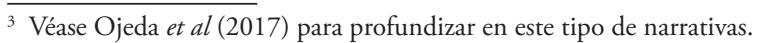


cios como estos podemos encontrar una identidad que permita nuestra autonomía como individuos, y la sororidad entre mujeres.

\section{Conclusiones}

En la conformación del yo online, tenemos que lidiar con los estereotipos de género. Toda disidencia de género suele ser penalizada, las mujeres, además, encontramos identidades online siempre mediadas por la masculinidad hegemónica, del varón, que se convierte en medida de todo.

La tecnología en sí no atiende a un sistema de relaciones de género determinado, pero la construcción de la misma y su uso sí lo hacen, acarreando que el medio virtual sea tan poco seguro como los medios analógicos en los que se socializa, o incluso menos seguro. El ocio online además está especialmente masculinizado, el mundo del videojuego y sus espacios adyacentes (chats como Discord o Team Speak, foros, plataformas de contenido como Youtube o Twitch) no se perfilan como como espacios neutros, y según los datos manejados (Reach3 Insights, 2021) más del 77\% de las encuestadas siente problemas al revelar su género cuando juega online.

No podemos concebir al ciudadano, a la persona, al individuo sin el mundo que le rodea, sin los espacios en los que habitamos, la tecnología que utilizamos, ni los flujos relacionales que nos rodean. Si este entorno deviene (o nace ya) hostil para la mujer, esto nos afecta tanto en nuestras relaciones como en nuestra propia identidad. Las mujeres (y otras identidades disidentes) tendemos a ser excluidas (o en ocasiones, hasta nos excluimos) de estas tecnologías creadas por y para una parte muy concreta de la población, hegemónica y masculinizada. Por este motivo es de capital importancia generar espacios y artefactos que no estén transidos por el sistema de relaciones de género que nos deja fuera. También cabe destacar que no hay identidades petrificadas o cerradas, sino que las líneas de fuga del sistema existen y un buen ejemplo de ello es el agenciamiento entre mujeres, arte y tecnología del colectivo web Terebi Magazine.

Como mantiene Eva Cid (2020), los videojuegos son espacios libérrimos donde podemos ser, pensar, y actuar de otro modo, pues actuamos bajo otras reglas. La ficción es un reflejo de nuestras inquietudes. También debería ser un espacio seguro desde el que experimentar con nuestros miedos, y también es un lugar de creación, de especulación, de posibles referencias ideológicas y herramientas que podemos usar, si no para arreglar el mundo, sí para imaginarle un futuro no tan oscuro. 


\section{REFERENCIAS BibLIOGRÁFICAS}

Amorós Puente, C. (1987). Espacio de los iguales, espacio de las idénticas. Notas sobre poder y principio de individuación. Arbor. Vol. 503-504 (pp. 113-128).

Bauman, Z. (2008). Identidad. Losada.

Cid Martínez, E. (2020). Civilización, apocalipsis y vestigio (o cómo el videojuego imagina nuestro futuro. Anait, (Recurso online: https://www.anaitgames. com/articulos/apocalipsis-y-vestigios-eva-cid).

Deleuze, G. y Guattari, F. (1985). Capitalismo y esquizofrenia. El anti-Edipo. Paidós.

Gamero Cabrera, Isabel G. (2012). ¿Qué implica ser "persona”? Thémata. Revista de Filosofía, vol. 46. Segundo Semestre. (pp. 675-682).

Garzón Costumero, X. (2021). Por mí y por todas mis compañeras. La mujer en la industria del videojuego, en A. C. Moreno Cantano y A. Venegas (eds.) La Vida en juego. Anait.

Haraway, D. (2020). Manifiesto Cyborg. Kaótika Libros.

Jodelet, D. (1986). La representación social: fenómenos, concepto y teoría, en S. Moscovici (ed.) Psicología Social II: Pensamiento y vida social. Psicología social $y$ problemas sociales. Paidós.

Lipset, S. M. y Rokkan, S. (1967). Party Systems and Voter Alignments. Free Press.

Mahler, A. (1997). Mi vida. Tusquets. (Recuperado de https://studylib.es/doc/7806794/1---biblioteca-digital-aecid).

Mead, G. H. (1928). Espiritu, persona y sociedad. Paidós.

Munné, F. (2000). El self paradójico: la identidad como substrato del self, en D. Caballero, Méndez y Pastor (eds.) La Mirada psicológica. Grupos, procesos, lenguajes y culturas. Biblioteca Nueva. (pp. 743-749).

Muros, B. (2011). El concepto de identidad en el mundo virtual: el yo online. Revista Electrónica Interuniversitaria de Formación del Profesorado, 14 (2). (pp. 49-56).

Ojeda, M. A. N., Romera, C. S. N., y Velasco, J. R. (2017). Estrategias de comunicación y narrativas transmedia: la promoción en entorno digitales de los videojuegos Diablo III y Diablo III, Reaper of Soul, en Territorios transmedia y narrativas audiovisuales. UOC. (pp. 91-108). 
Rubio, M. y Cabañes, E. (2012). El sexo de los píxeles. Del yo-mujer al yo-tecnológico. Revista de Estudios de Juventud, 98, (pp. 150-166).

Judy Wajcman (2004). TechnoFeminism. Polity.

Zafra, R. (2010). Un cuarto propio conectado. (Ciber)espacio y (auto)gestión del yo. Fórcola.

\section{Otros RECURSOS}

Reach3 Insights (2021). New Research Reveals 59\% of Women Surveyed Use a Non-Gendered/Male Identity to Avoid Harassment While Gaming (Recuperado de https://www.reach3insights.com/women-gaming-study).

Terebi Magazine (https://terebimagazine.es/).

DOI: https://doi.org/10.15366/bp2021.28.010

Bajo Palabra. II Época. No28. Pgs: 217-236 
